\title{
Alternative Sample Preparation Techniques in Gas Chromatographic- Mass Spectrometric Analysis of Urinary Androgenic Steroids
}

\author{
Young-Dae Cho ${ }^{\phi+\hat{*}}$ and Man Ho Choi ${ }^{+* *}$ \\ ${ }^{\dagger}$ Doping Control Center, Korea Institute of Science and Technologv, Seoul 136-791, Korea. "E-mail: mh_choi@kistrekr. \\ ${ }^{+}$Department of Chemistry, Kning Hee University, Seonl 130-701, Korea \\ Received March 14, 2006
}

\begin{abstract}
The following study describes the gas chromatography-mass spectrometry (GC-MS) based screening and contirmation analysis of urinary androgenic steroids. Four commercially available solid-phase extraction (SPE) cartridges, Serdolit $\mathrm{P} \Lambda \mathrm{D}-1$, Sep-pak $\mathrm{C}_{18}$, amino-propyl, and $\mathrm{O}$ asis ILB, and three different extractive organic solvents, diethyl ether, methyl tert-butyl ether (MTBE), and n-pentane, were tested for sample preparation. Overall, Oasis ILB combined with MTBE extraction provided the highest recoveries in 39 of 46 total androgenic steroids examined and it showed a good extraction yield ( $>82.1 \%$ ) for polar steroids, such as metabolites of fluoxymesterone, oxandrolone, and stanozolol, which gave a poor recovery in both $n$-pentane (9.2-64.3\%) and diethyl ether (22.2-73.6\%) extractions. $\Lambda$ ll SPE sorbents tested showed potential, because they were efficient in extraction for most or selective steroids. When applied to positive urine samples based on the results obtained, the present method allowed selective and sensitive analysis for detection of urinary androgenic steroids. The experiments showed that the high-resolution MS method is clearly more efficient than the lowresolution MS technique for the detection of many urinary steroids. Ilowever, comprehensive sample clean-up procedures also might be needed especially in confirmation analysis to increase detectability.
\end{abstract}

Key Words : Solid-phase extraction, Steroids, Mass spectrometry, Doping control

\section{Introduction}

The analytical method for urinary steroids in doping control is usually performed on urine extracts where synthetic and endogenous androgenic steroids, or their main metabolites, have to be distinguished from numerous endogenous steroids and other polar substances. ${ }^{1-3}$ To achieve exact identification at lower concentrations, the sample preparation technique must provide a good yield and selectivity. Hence, two effective methods, the additional amino-column purification ${ }^{4}$ and the extraction with non-polar solvent $n$-pentane ${ }^{5}$ are proposed on general extraction procedure ${ }^{2,6}$ to remove disturbing urinary backgrounds. But, these clean-up steps are not suitable for the detection of relatively polar steroids, such as metabolites of stanozolol (17 $\alpha$-methyl-17 $\beta$-hydroxy- $5 \alpha-$ androstano-[3,2-C]-pyrazole), which its pyrazole nucleus attached on the steroidal A-ring, and extractive $N$-alkyloxycarbonylation $(N-A O C)$ was therefore introduced as an alternative technique. ${ }^{7}$ Although $N$-AOC method improved not only sample recovery but chromatographic properties of major metabolite of stanozolol, 3-hydroxystanozolol, it was not suitable for other polar steroid molecules.

Prior to gas chromatographic-mass spectrometric (GCMS) analysis, it is prerequisite to isolate steroids from complex biological specimens and the solid-phase extraction (SPE) method is preferentially used when decreasing sample complexity are required for the simultaneous detection of urinary steroids in both screening and confirmation analyses. Many SPE procedures employing silica-based non-polar sorbent Sep-Pak ${ }^{\mathrm{TM}} \mathrm{C}_{18}$ and polar sorbent amino-propyl $\left(\mathrm{NH}_{2}\right)$ columns were $\mathrm{pH}$ dependent and thus slight sample loss was unavoidable. The, $\mathrm{pH}$ durable co-polymeric sorbents such as $\mathrm{XAD}^{\mathrm{TM}}$ (styrene and divinylbenzene: $\mathrm{SDB}$ ) and Oasis HLB ${ }^{\mathrm{TM}}$ (divinylbenzene and $N$-vinylpyrrolidone) could be more preferable for the sample clean-up of steroidal compounds. ${ }^{7-10}$ The SPE methods can be limited by the difficulty of choosing from a large variety of SPE sorbents and by the different chemical properties of urinary steroids for simultaneous analysis. These methods are also combined with enzymatic hydrolysis and additional liquidliquid extraction (LLE) steps to extract un-conjugated steroids.

As the efficient screening and conformation methods in doping control and clinical applications, this study has been focused on the improved recovery and detectability of synthetic and endogenous androgenic steroids in human urine. The present method is based on SPE and LLE techniques, which are employed to optimize sample preparation steps. After optimizing with SPE cartridges and organic solvents tested, the comprehensive extraction and purification methods were applied for the analysis of 46 androgenic steroids by both GC-low-resolution MS and GC-high resolution MS (GC-LRMS and GC-HRMS).

\section{Experimental Section}

Chemicals. The 46 androgenic steroids consists of synthetic drugs and urinary metabolites (Table 1) and $17-^{2} \mathrm{H}_{3}-3-$ $\mathrm{OH}$-stanozolol as one of internal standards were obtained from Sigma (St. Louis, CA, USA), Steraloids (Newport, RI, USA), NARL (Pumble, Australia), and Cologne Laboratory (German Sports University, Köln, Germany). Other two internal standards, $16,16,17-{ }^{2} \mathrm{H}_{3}$-testosterone and $16,16,17-$ 
${ }^{2} \mathrm{H}_{3}$-epitestosterone, were obtained from Cologne Laboratory. The trimethylsilylating agents, $N$-methyl- $N$-trifluorotrimethylsilyl acetamide (MSTFA), ammonium iodide $\left(\mathrm{NH}_{4} \mathrm{I}\right)$, and dithioerythritol (DTE), were purchased from Sigma. The $50 \%$ glycerol solution of $\beta$-glucuronidase from $E$-coli $(140 \mathrm{U} / \mathrm{mL}$ ) was purchased from Boehringer Mannheim

Table 1. Abbreviations of androgenic steroids and their GC-MS information

\begin{tabular}{|c|c|c|c|c|}
\hline Abbreviation & Nomenclature & M.W. & R.T. & Ions selected \\
\hline \multicolumn{5}{|c|}{ Anabolic androgenic steroids } \\
\hline Calusterone-M & $7 \beta, 17 \alpha$-dimethyl-5 $\beta$ androstane- $3 \alpha, 17 \beta$-diol & 320 & 12.22 & $284,374,449$ \\
\hline $16 \beta-O \mathrm{H}$-fitrazabol & $16 \beta, 17 \beta$-dihydroxy-17 $\alpha$-methyl-5 $\alpha$-androstane $[2,3$-c] furan & 346 & 18.25 & $218,231,490$ \\
\hline $3^{\prime}-\mathrm{OH}$-stanozolol & $3^{+}$-hydroxy-1 $7 \alpha$-methyl-1 $7 \beta$ hydroxy-5 $\alpha$-androstano-(3,2-c)-pyrazole & 344 & 18.60 & $254,545,560$ \\
\hline Bolasterone-M & $7 \alpha, 17 \alpha$-dimethyl-5 $\beta$-androstane- $3 \alpha, 17 \beta$-diol & 320 & 12.67 & $143,374,284$ \\
\hline Bolasterone & $7 \alpha, 17 \alpha-$ dimethyl-17 $\beta$-hydroxyandrost-4-en-3-one & 316 & 13.78 & $445,315,460$ \\
\hline Boldenone-M & $17 \beta$-hydroxy-5 $\beta$-androst-1-en-3-one & 288 & 8.84 & $194,432,417$ \\
\hline Boldenone & $17 \beta$-hydroxyandrosta-1,4-dien-3-one & 286 & 11.94 & $206,430,415$ \\
\hline Boldione & 1,4-androstadienone-3,17-dione & 284 & 11.72 & $428,413,323$ \\
\hline Colstebol-M & 4-chloro-3 $\alpha$-hydroxyandrost-4-en-17-one & 322 & 12.69 & $466,451,468$ \\
\hline Methandienone-M1 & $6 \beta, 17 \beta$-dihydroxy-17-methyl-1,4-androstadien-3-one & 304 & 8.86 & $216,358,448$ \\
\hline Methandienone-M2 & 17-epi-17 $\beta$-hydroxy-17-methyl-1,4-androstadien-3-one & 316 & 15.78 & $517,294,532$ \\
\hline Drostanolone-M & $3 \alpha$-hydroxy-2 $\alpha$-methyl- $5 \alpha$-androstan-17-one & 304 & 10.46 & $433,448,343$ \\
\hline Ethisterone & $17 \alpha$-ethinyl- $17 \beta$-hydroxyandrost-4-en-3-one & 312 & 13.96 & $456,301,441$ \\
\hline Flıoxymesterone-M1 & 9-fluoro-17 $\alpha$-methylandrost-4-ene-3 $3 \alpha, 6 \beta, 11 \beta, 17 \beta$ tetrol & 354 & 15.28 & $143,552,642$ \\
\hline Formebolone-M & 2-hydroxymethyl-11 $\alpha, 17 \beta$-dihydroxy-17 $\alpha$-methylandrosta-1,4-dien-3-one & 346 & 17.62 & $351,439,634$ \\
\hline Metenolone-M1 & $3 \alpha$-hydroxy-1-methylen-5 $\alpha$-androatan-17-one & 302 & 10.90 & $431,446,341$ \\
\hline Methyltestosterone-M1 & $17 \alpha$-methyl-5 $\alpha$-androstane- $3 \alpha, 17 \beta$-diol & 306 & 11.34 & $435,255,270$ \\
\hline Methyltestosterone-M2 & $17 \alpha$-methyl- $5 \alpha$-androstane- $3 \alpha, 17 \beta$-diol & 306 & 11.42 & $435,255,270$ \\
\hline Mibolerone & $17 \beta$-hydroxy-7 $\alpha, 17 \alpha$-dimethylestra-4-en-3-one & 302 & 13.14 & $431,446,341$ \\
\hline 19-Norandrosterone & $3 \alpha$-hydroxy-5 $\beta$-estran-17-one & 276 & 8.62 & $405,420,315$ \\
\hline 19-Noretiocholanolone & $3 \alpha$-hydroxy-5 $\alpha$-estran-17-one & 276 & 9.42 & $405,420,315$ \\
\hline$\alpha-$ Norbolethone & 13-ethyl-17-hydroxy-18,19-dinor-17 $\alpha$-pregn-4-en-3-one & 420 & 13.04 & $157,435,255$ \\
\hline$\beta$ Norbolethone & 13-ethyl-17-hydroxy-18,19-dinor-17 $\beta$-pregn-4-en-3-one & 420 & 14.14 & $157,435,255$ \\
\hline Norethandrolone-M & $17 \alpha$-ethyl- $5 \beta$-estrane- $3 \alpha, 17 \beta$-diol & 306 & 15.30 & $157,421,331$ \\
\hline Oral-turinabol-M & $6 \beta, 16 \beta$-dihydroxy-4-chlorodehydromethyltestosterone & 350 & 17.02 & $315,143,317$ \\
\hline Oxandrolone-M & 17-epi-17 $\beta$-hydroxy-17 $\alpha$-methyl-2-oxa-5 $\alpha$-androstan-3-one & 306 & 12.38 & $308,363,321$ \\
\hline Oxandrolone & $17 \beta$-hydroxy-17 $\alpha$-methyl-2-oxa-5 $\alpha$-androstan-3-one & 306 & 14.09 & $308,363,321$ \\
\hline Oxymesterone & $4,17 \beta$-dihydroxy-17 $\alpha$-methylandrost-4-en-3-one & 318 & 16.46 & $534,389,519$ \\
\hline$\alpha$-Trenbolone & 17-epi-17 $\beta$ hydroxyestra-4,9,11-trien-3-one & 270 & 11.68 & $307,412,322$ \\
\hline$\beta$ Trenbolone & $17 \beta$-hydroxyestra-4,9,11-trien-3-one & 270 & 12.44 & $307,412,322$ \\
\hline \multicolumn{5}{|c|}{ Endogenous androgenic steroids } \\
\hline 11-keto-androsterone & $3 \alpha$-hydroxy-5 $\alpha$-androstane-11,17-dione & 304 & 11.04 & 520 \\
\hline 11-keto-etiocholanolone & $3 \alpha$-hydroxy-5 $\beta$-androstane-11,17-dione & 304 & 11.11 & 520 \\
\hline $11 \beta \mathrm{OH}$-androsterone & $3 \alpha, 11 \beta$-dihydroxy-5 $\alpha$-androstan-17-one & 306 & 12.42 & 522 \\
\hline $11 \beta O H$-etiocholanolone & $3 \alpha, 11 \beta$-dihydroxy-5 $\beta$-androstan-17-one & 306 & 12.59 & 522 \\
\hline 4-Andro-3,17-dione & 4-androstene-3,17-dione & 270 & 11.91 & 430 \\
\hline $5 \alpha$-andro-3,17-dione & $5 \alpha$-androstane-3,17-dione & 288 & 11.93 & 432 \\
\hline $5 \alpha$-andro- $3 \alpha, 17 \beta$-diol & $5 \alpha$-androstan- $3 \alpha, 17 \beta$ diol & 292 & 10.16 & 436 \\
\hline $5 \alpha$-andro- $3 \beta, 17 \beta$-diol & $5 \alpha$-androstan- $3 \beta, 17 \beta$-diol & 292 & 10.24 & 436 \\
\hline Androstenediol & 5 -androsten- $3 \beta, 17 \beta$-diol & 290 & 11.37 & 434 \\
\hline Androstenedione & 4-androsten-3, 17-dione & 286 & 11.91 & 430 \\
\hline Androsterone & $3 \alpha$-hydroxy-5 $\alpha$-androstan-17-one & 290 & 9.91 & 434 \\
\hline DHEA & $5 \alpha$-androsten- $3 \beta$-ol-17-one & 288 & 11.06 & 432 \\
\hline $\mathrm{DHT}$ & $5 \alpha$-androstan-17 $\beta$-ol-3-one & 290 & 11.70 & 434 \\
\hline Epitestosterone & $17 \alpha$-hydroxy-4-androsten-3-one & 288 & 11.39 & 432 \\
\hline Etiocholanolone & $3 \alpha$-hydroxy-5 $\beta$-androstan-17-one & 290 & 10.05 & 434 \\
\hline Testosterone & $17 \beta$-hydroxyandrost-4-en-3-one & 288 & 12.18 & 432 \\
\hline
\end{tabular}

Molecular weights as their underivatives. "Retention times separated on Ultra-l capillary column ( $17 \mathrm{~m} \times 0.2 \mathrm{~mm}$ I.D., 0.11 mm film thickness); the initial temperature was $180^{\circ} \mathrm{C}$, ramped to $240^{\circ} \mathrm{C}$ at $4{ }^{\circ} \mathrm{C} / \mathrm{min}$ and then finally to $320^{\circ} \mathrm{C}$ (hold $3.67 \mathrm{~min}$ ) at $15^{\circ} \mathrm{C} / \mathrm{min}$. 
(Mannheim, Germany). In SPE experiments, four hydrophilic sorbents, Oasis HLB ${ }^{\mathrm{TM}}$ ( $3 \mathrm{~mL}$, $60 \mathrm{mg}$; Waters; Milford, MA, USA), Sep-pak ${ }^{\mathrm{TM}} \mathrm{C}_{18}\left(3 \mathrm{~mL}, 200 \mathrm{mg}\right.$; Waters), Serdolit ${ }^{\mathrm{TM}}$ PAD-1 $\quad 0.1-0.2 \mathrm{~mm}$ analytical grade; Serva; Hiedelberg, Germany), and Amino-propyl ( $\mathrm{NH}_{2}: 3 \mathrm{~mL}, 200 \mathrm{mg}$; Waters) preconditioned with $15 \mathrm{~mL}$ of methanol followed by $15 \mathrm{~mL}$ of deionized water were prepared.

Diethyl ether as one of extraction solvents was distilled from calcium hydride powder just before being used. Other organic solvents used as the analytical and HPLC grade were purchased from Burdick \& Jackson (Muskegan, MI, USA). Deionized water was prepared by Milli-Q purification system (Millipore; Billerica, MA, USA).

Preparation of standard solution. Each stock solution of reference standards was prepared at concentration of 1,000 $\mu \mathrm{g} / \mathrm{mL}$ in methanol. Each working standard solution was made up with methanol at varied concentrations in the range of 0.1 to $10 \mu \mathrm{g} / \mathrm{mL}$. All standard solutions were stored at $-20^{\circ} \mathrm{C}$ until being used.

Urine samples. The urine sample was prepared with a first-moning urine obtained from a healthy male volunteer by spiking 30 exogenous steroids at the urinary concentrations of $40 \mathrm{ng} / \mathrm{mL}$. The same amounts of endogenous steroids were also added and the level of each endogenous steroid was relatively increased depending on the kind of endogenous steroid presented. The methods optimized were completed on human spiked and positive urine samples. All samples were frozen at $-20^{\circ} \mathrm{C}$ and archived until being extracted. Whether freeze-thaw cycles occurred prior to analysis of the sample is unknown.

Sample preparation. All SPE cartridges preconditioned were placed in a device fitted with a small vacuum pump and a waste receiver. Each urine sample $(2 \mathrm{~mL})$ prepared was slowly loaded to the cartridge, followed by washing twice with water $(1 \mathrm{~mL})$ and then eluted with $2 \mathrm{~mL}$ methanol in twice. The combined methanol extract was evaporated to dryness using rotary evaporator, and the resulting residues were subjected to enzymatic hydrolysis. Briefly, the residue was dissolved in $1 \mathrm{~mL}$ of phosphate buffer $(0.2 \mathrm{~mol} / \mathrm{L}, \mathrm{pH}$ 7.2) and $50 \mu \mathrm{L}$ of $\beta$-glucuronidase, and the mixture was heated for $1 \mathrm{~h}$ at $55^{\circ} \mathrm{C}$. After cooling at room temperature, $0.7 \mathrm{~mL}$ of $5 \% \mathrm{~K}_{2} \mathrm{CO}_{3}$ was added to adjust $\mathrm{pH} 9.6$, and then added with different organic solvents $(5 \mathrm{~mL})$, such as diethyl ether, methyl tert-butyl ether, and $n$-pentane. Each mixture was shaken $(10 \mathrm{~min})$, centrifuged $(5 \mathrm{~min}, 1200 \mathrm{~g})$, and the phase separation was achieved by placing the tube in a dry ice-acetone bath (about $-30^{\circ} \mathrm{C}$ ). The organic extract was evaporated to dryness by $\mathrm{N}_{2}$ evaporator at $40^{\circ} \mathrm{C}$. The dried residue was further dried in a vacuum desiccator over $\mathrm{P}_{2} \mathrm{O}_{5}-$ $\mathrm{KOH}$ for $30 \mathrm{~min}$ and then derivatized with $50 \mu \mathrm{L}$ of MSTFA $/ \mathrm{NH}_{4} \mathrm{I} / \mathrm{DTE}(500: 4: 2, \mathrm{v} / \mathrm{w} / \mathrm{w})$ for $20 \mathrm{~min}$ at $60^{\circ} \mathrm{C}$. The sample $(2 \mu \mathrm{L})$ was injected into GC-MS and GCHRMS systems as described in follow section.

Gas chromatography-mass spectrometry. GC-LRMS analysis in the selected-ion monitoring (SIM) mode was performed with an Agilent 6890 plus gas chromatograph interfaced to an Agilent 5973 MSD (Agilent; Avondale, PA,
USA) employing an Ultra-1 fused-silica capillary column $(17 \mathrm{~m} \times 0.2 \mathrm{~mm}$ I.D., $0.11 \mu \mathrm{m}$ film thickness; Agilent). The electron energy was $70 \mathrm{eV}$, and the ion source temperature was $230^{\circ} \mathrm{C}$. The carrier gas was helium at a column head pressure of $100 \mathrm{kPa}$ (column flow: $0.6 \mathrm{~mL} / \mathrm{min}$ ) with injector temperature of $280^{\circ} \mathrm{C}$. The sample was injected with split $(1: 10)$ mode and the temperature program was as follows: the initial temperature was $180^{\circ} \mathrm{C}$, ramped to 240 ${ }^{\circ} \mathrm{C}$ at $4{ }^{\circ} \mathrm{C} / \mathrm{min}$ and then finally to $320^{\circ} \mathrm{C}$ (hold $3.67 \mathrm{~min}$ ) at $15^{\circ} \mathrm{C} / \mathrm{min}$.

For the HR/SIM analysis, high resolution mass spectrometer (JMS700, Jeol; Tokyo, Japan) was conducted with the same capillary column at resolution 5,000. Each sample (2 $\mu \mathrm{L}$ ) was injected in split mode $(1: 5)$ at $280^{\circ} \mathrm{C}$ of injector temperature, and the oven temperature was initially at 180 ${ }^{\circ} \mathrm{C}$, ramped to $220^{\circ} \mathrm{C}$ at $5^{\circ} \mathrm{C} / \mathrm{min}$, ramped to $260^{\circ} \mathrm{C}$ (hold for $2 \mathrm{~min}$ ) at $6^{\circ} \mathrm{C} / \mathrm{min}$ and then finally to $310^{\circ} \mathrm{C}$ (hold for $3.83 \mathrm{~min}$ ) at $20^{\circ} \mathrm{C} / \mathrm{min}$. Helium carrier gas was set to a column head pressure of $79 \mathrm{kPa}$ (column flow: $0.4 \mathrm{~mL} / \mathrm{min}$ ). Accelerator voltage and reservoir temperature were $10 \mathrm{kV}$ and $80^{\circ} \mathrm{C}$, respectively.

Data acquisition and interpretation. In both LR/SIM and HR/SIM modes, the present method was designed that three characteristic ions for each synthetic steroid and one ion for each endogenous steroid were selected on the basis of their mass fragmentation (Table 1). The peak identification was achieved by comparing the retention times and the area ratios of characteristic ions with those of respective reference standards. A relative electron multiplier voltage of $400 \mathrm{~V}$ higher than that in the scanning mode was chosen for each ion monitored in GC-LR/SIM-MS analysis.

The urine samples prepared were subjected to SPE and derivatization with subsequent analysis by GC-LRMS and GC-HRMS analyses. The recovery of each steroid was assessed by comparing peak area ratios of extracted samples to non-extracted counterparts representing $100 \%$ recovery in duplicate, and then the extraction efficiency was determined by ordering the extraction recoveries.

\section{Results and Discussion}

Evaluation of extraction efficiency. The efficiencies of extraction solvents were tested with diethyl ether, MTBE, and $n$-pentane combined with each SPE purification procedure studied. The overall recovery increased along with increasing polarity of solvents, but $n$-pentane demonstrated better selectivity for some androgenic steroids to remove the interference background signals. Boldenone was well detected without significant interfering peaks in both extraction methods, but boldenone at $m / z 415$ and 430 was detected with diminished interfering peak (Figure 1). 3-OH-stanozolol was extracted from urine with a lower recovery than other urinary steroids because of its polar structure, in which its pyrazole nucleus is attached on the steroidal A-ring. The $n$ pentane extraction procedure to removing disturbing backgrounds especially offered little recovery with about $6 \%$ yield for 3-OH-stanozolol, while extraction with MTBE 

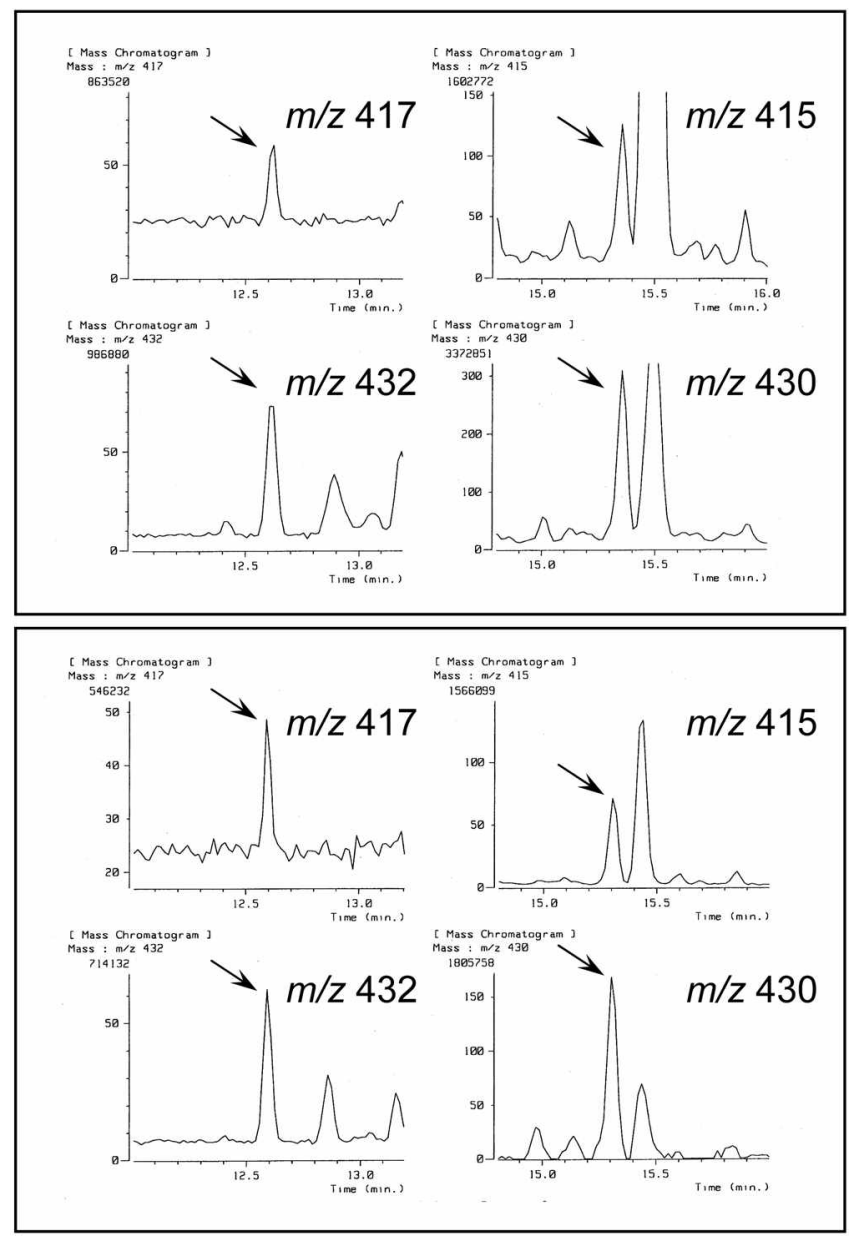

Figure 1. Extracted-ion chromatograms of boldenone $(\mathrm{m} / 2415$ and 430 ) and its metabolite ( $m / 2417$ and 432) obtained from methyl tert-butyl ether (upper panel) and n-pentane (lower panel) extractions. The oven temperature for GC-HRMS analysis was initially at $180^{\circ} \mathrm{C}$, ramped to $220^{\circ} \mathrm{C}$ at $5^{\circ} \mathrm{C} / \mathrm{min}$, ramped to $260^{\circ} \mathrm{C}$ (hold for 2 min) at $6^{\circ} \mathrm{C} / \mathrm{min}$ and then finally to $310^{\circ} \mathrm{C}$ (hold for $3.83 \mathrm{~min}$ ) at $20^{\circ} \mathrm{C} / \mathrm{min}$.

leaus to an excelient extraction.

The LLE only method on doping procedure was also evaluated by 3 different organic solvents. The LLE extraction methods showed good recovery yields in most analytes, but some androgenic steroids overlapped with significant urinary background signals and could not be separated in GC-MS analysis (data not shown). Extraction with MTBE maximized the recoveries in many androgenic steroids no matter which SPE cartridges were combined (Figure 2). The recoveries of 3-OH-stanozolol, and other androgenic steroids included in the screening procedure without SPE method, ranged from $72.4 \%$ to $96.5 \%$, except for the major metabolite of fluoxymesterone $(64.1 \%)$. This indicates that diethyl ether and MTBE had good recoveries and could be used in the extraction of many urinary androgenic steroids, while $n$-pentane could be used in confinmation analysis with selected analytes (Table 2). In addition, most androgenic steroids examined in this study are slightly polar and thus prone to be lost during the washing of SPE cartridges with

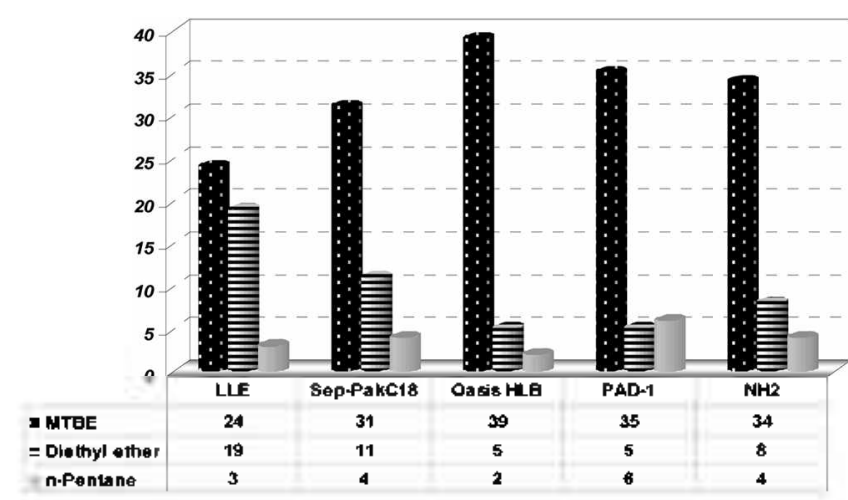

Figure 2. Effects of the organic solvents on the extraction efficiency combined with each solid-phase extraction and liquidliquid extraction only. After adjustment $\mathrm{pH} 9.6$ of sample mixture, different organic solvents $(5 \mathrm{~mL})$, such as diethyl ether, methyl tertbutyl ether, and $n$-pentane, added and isolated (see detail "sample preparation" section).

water.

In consequent study, the extraction efficiency of analytes was also evaluated with many SPE cartridges and different LLE organic solvents. The cartridges were limited to $3 \mathrm{~mL}$ capacity to directly compare with Serdolit PAD-1 sorbent commonly used in doping control. ${ }^{7}$ In the attempt to maximize recovery of many androgenic steroids, we easily established that polar compounds demonstrated low recoveries by Sep-pak $\mathrm{C}_{18}$, amino-propyl and Serdolit PAD1 columns, while Oasis HLB cartridge increased recoveries of polar compounds, such as fluoxymesterone-MI and 3$\mathrm{OH}$-stanozolol. The Oasis HLB extraction cartridge seems suitable for relatively polar compounds and this cartridge also showed good recoveries in many androgenic steroids studied. This is in accord with that Oasis HLB provided selective isolation and enrichment of polar steroid compounds, such as estrogens, from the complex biological specimens. ${ }^{8.10}$ In addition, the Oasis HLB cartridge contains a unique copolymer sorbent with hydrophilic and lipophilic groups in proportions that allow high and reproducible recoveries of many compounds..$^{7-13}$ Among SPE cartridges tested, the amino-propyl had lower sample recoveries than other SPE cartridges tested. Overall, Oasis HLB provided the highest recoveries in many androgenic steroids and thus chosen conducted with MTBE extraction (Table 2). All sorbents tested showed potential, because they were efficient in extraction for most or selective analytes.

GC-LRMS and GC-HRMS analyses. Under the present GC-LRMS and GC-HRMS conditions, baseline resolution of all steroids examined, except for the dual pairs of stable isotope labeled and unlabeled testosterone and epitestosterone, were achieved as their TMS derivatives in one analytical run within $24 \mathrm{~min}$. Each androgenic steroid analyzed a single peak with symmetric shape and the accurate peak identification was furnished by the three characteristic ions selected in LR/SIM mode (Table 1). The unresolved 2 compounds in each pair were distinguishable enough to be quantified in SIM mode on each selected ions 
Table 2. Extraction yields (\%) resulted from $\$ P E$ methods of Oasis HLB and amino-propyl cartridges

\begin{tabular}{|c|c|c|c|c|c|c|}
\hline \multirow{2}{*}{ Substance } & \multicolumn{3}{|c|}{ Oasis HLB } & \multicolumn{3}{|c|}{ Amino-propyl $\left(\mathrm{NH}_{2}\right)$} \\
\hline & Ether & MTBE & $n$-pentane & Ether & MTBE & $n$-pentane \\
\hline \multicolumn{7}{|l|}{ Anabolic androgenic steroids } \\
\hline Calusterone-M & 88.3 & 72.6 & 52.4 & 72.4 & 66.5 & 42.9 \\
\hline $16 \beta-0 \mathrm{H}$-furazabol & 78.9 & 83.6 & 39.4 & 63.2 & 62.5 & 33.0 \\
\hline 3'-OH-stanozolol & 73.6 & 92.1 & 12.5 & 72.9 & 78.4 & 9.2 \\
\hline Bolasterone-M & 72.9 & 89.3 & 78.5 & 74.9 & 78.4 & 65.2 \\
\hline Bolasterone & 75.8 & 90.2 & 82.3 & 70.3 & 80.3 & 74.2 \\
\hline Boldenone-M & 82.3 & 80.4 & 86.3 & 80.5 & 72.6 & 83.9 \\
\hline Boldenone & 85.5 & 91.3 & 79.0 & 87.1 & 88.2 & 79.3 \\
\hline Boldione & 82.6 & 88.9 & 73.1 & 79.3 & 85.2 & 69.4 \\
\hline Colstebol-M & 74.2 & 93.1 & 84.6 & 70.2 & 90.6 & 83.1 \\
\hline Methandienone-M1 & 71.5 & 81.2 & 89.1 & 84.4 & 64.2 & 70.9 \\
\hline Methandienone-M2 & 74.7 & 85.7 & 80.3 & 74.6 & 82.5 & 70.2 \\
\hline Drostanolone-M & 90.2 & 95.3 & 84.2 & 85.5 & 91.2 & 86.1 \\
\hline Ethisterone & 84.1 & 93.5 & 87.3 & 82.4 & 90.5 & 88.6 \\
\hline Fluoxymesterone-M1 & 58.1 & 82.1 & 20.6 & 22.2 & 26.3 & 6.3 \\
\hline Formebolone-M & 75.4 & 85.8 & 77.3 & 80.6 & 82.4 & 71.0 \\
\hline Metenolone-Ml & 85.3 & 89.5 & 80.0 & 72.1 & 83.2 & 75.2 \\
\hline Methyltestosterone-M1 & 86.2 & 92.1 & 85.9 & 83.2 & 85.2 & 75.6 \\
\hline Methyltestosterone-M2 & 80.4 & 82.5 & 75.9 & 78.4 & 82.5 & 72.2 \\
\hline Mibolerone & 81.2 & 87.2 & 84.0 & 82.9 & 84.1 & 75.5 \\
\hline 19-Norandrosterone & 89.7 & 97.3 & 92.6 & 85.2 & 76.2 & 84.1 \\
\hline 19-Noretiocholanolone & 85.7 & 93.1 & 90.5 & 76.3 & 75.9 & 80.3 \\
\hline$\alpha-$ Norbolethone & 82.5 & 79.2 & 70.4 & 72.6 & 84.2 & 78.5 \\
\hline$\beta$ Norbolethone & 82.6 & 87.5 & 79.5 & 79.5 & 80.3 & 76.2 \\
\hline Norethandrolone-M & 85.9 & 86.4 & 76.8 & 83.6 & 84.4 & 77.2 \\
\hline Oral-turinabol-M & 82.3 & 85.8 & 80.9 & 78.4 & 80.2 & 73.3 \\
\hline Oxandrolone-M & 69.1 & 87.2 & 64.3 & 73.2 & 64.6 & 58.5 \\
\hline Oxandrolone & 82.3 & 87.9 & 78.1 & 68.8 & 80.3 & 70.1 \\
\hline Oxymesterone & 82.4 & 90.3 & 87.1 & 82.9 & 91.3 & 86.5 \\
\hline$\alpha$-Trenbolone & 81.3 & 83.9 & 68.6 & 74.1 & 79.3 & 62.0 \\
\hline$\beta$-Trenbolone & 85.9 & 88.1 & 72.2 & 83.5 & 84.1 & 60.4 \\
\hline \multicolumn{7}{|c|}{ Endogenous androgenic steroids } \\
\hline 11-keto-androsterone & 91.6 & 93.5 & 75.2 & 80.2 & 84.1 & 70.3 \\
\hline 11-keto-etiocholanolone & 94.9 & 96.2 & 78.8 & 85.3 & 82.9 & 80.7 \\
\hline $11 \beta \mathrm{OH}$-androsterone & 89.4 & 93.5 & 76.2 & 86.7 & 85.8 & 73.6 \\
\hline $11 \beta \mathrm{OH}$-etiocholanolone & 82.4 & 83.0 & 80.8 & 78.7 & 83.1 & 72.9 \\
\hline 4-Andro-3,17-dione & 84.5 & 87.2 & 78.5 & 79.4 & 86.2 & 80.0 \\
\hline $5 \alpha$-andro-3,17-dione & 83.4 & 88.6 & 74.5 & 74.8 & 82.8 & 70.1 \\
\hline $5 \alpha$-andro- $3 \alpha, 17 \beta$-diol & 84.2 & 92.2 & 85.5 & 82.5 & 90.1 & 83.9 \\
\hline $5 \alpha$-andro- $3 \beta, 17 \beta$-diol & 82.5 & 90.5 & 84.6 & 80.5 & 93.0 & 82.7 \\
\hline Androstenediol & 83.7 & 90.1 & 85.1 & 82.1 & 90.5 & 80.4 \\
\hline Androstenedione & 87.2 & 91.7 & 82.7 & 80.8 & 89.6 & 81.3 \\
\hline Androsterone & 97.2 & 95.4 & 89.3 & 88.9 & 85.6 & 91.6 \\
\hline DHEA & 83.5 & 84.1 & 82.1 & 86.4 & 79.3 & 81.4 \\
\hline DHT & 90.4 & 96.4 & 85.3 & 82.9 & 83.6 & 85.7 \\
\hline Epitestosterone & 90.3 & 95.2 & 87.5 & 85.7 & 94.0 & 90.2 \\
\hline Etiocholanolone & 94.1 & 92.1 & 86.7 & 84.8 & 92.5 & 85.2 \\
\hline Testosterone & 93.7 & 92.7 & 89.5 & 92.3 & 91.4 & 89.1 \\
\hline
\end{tabular}

(Figure 3) and HR/SIM analysis at resolution 5,000 was found very complementary in further confirmation of small peaks pre-identified especially when they were present at trace levels in steroid analysis. ${ }^{1+-16}$ It is important to note that the sensitivity is inversely proportional to the resolution in GC-HRMS analysis. The resolution used in a particular 

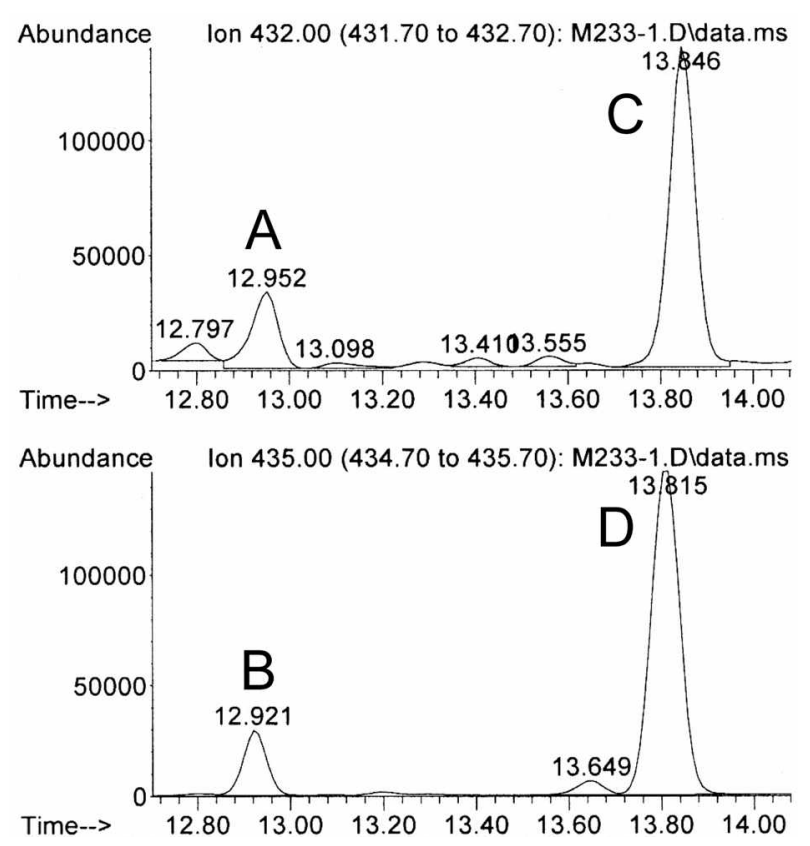

Figure 3. GC-LR/SIM-MS chromatograms for detection of (A) epitestostcrone, (B) $d$-epitestosterone, (C) testosterone, (D) $d$;testosterone. The temperature program for GC-MS analysis was as follows: the initial temperature was $180^{\circ} \mathrm{C}$, ramped to $240^{\circ} \mathrm{C}$ at 4 ${ }^{\circ} \mathrm{C} / \mathrm{min}$ and then finally to $320^{\circ} \mathrm{C}$ (hold $3.67 \mathrm{~min}$ ) at $15^{\circ} \mathrm{C} / \mathrm{min}$.

analysis, therefore, depends on the sensitivity required and the level of background noise. In HRMS analysis, the reduction of measurement of masses to narrow ranges permits a discrimination of background signals from analytes of interest. The desirable resolution for a measurement can be optimized by the mass difference between signal and background noise. This difference is usually unknown, as the interferences are unidentified. The effect of an increase of the mass resolution, therefore, can be predicted only with
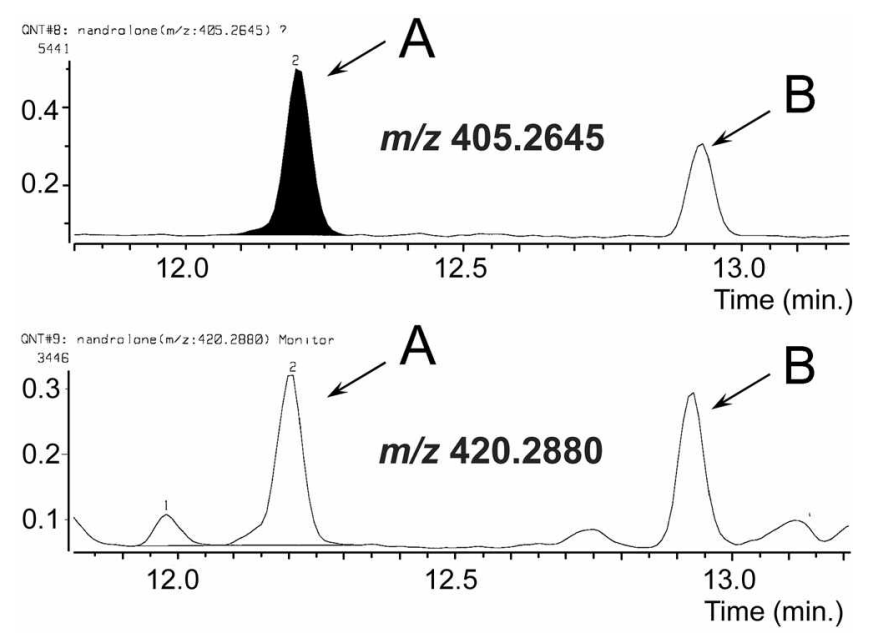

Figure 4. GC-HR/SIM-MS chronatograms at $m / z 405.2645$ and 420.2880 for detection of $(A)$ 19-norandrosterone and $(B)$ 19noretiocholanolone at the urinary concentration of $0.2 \mathrm{ng} / \mathrm{mL}$ after Oasis HLB and methyl teri-butyl ether extraction steps. Resolution was 5,000 and other GC-HRMS conditions are the same as in Figure 2. some difficulty. Here, the resolution was referred to a mostly detected steroid in doping control, 19-norandrosterone (19NA) by co-eluting vitamin E metabolite, ${ }^{17}$ and HRMS analysis at resolution 5,000 was employed to distinguish 0.1 Da differences.

The eluant from the Oasis HLB cartridge still contained interference background signals in detection of 19-NA and 19-noretiocholanolone (19-NE), and GC-HRMS analysis therefore was engaged to improve detectability. Although additional purification steps are available, for a comprehensive method involving the sensitive and selective analysis was required. In addition, GC-HRMS analysis with HR/SIM mode was an essential technique and this analysis not only allowed good selectivity at resolution 5,000 but also served as the sensitive detection method for two urinary steroids, 19-NA and 19-NE, as well (Figure 4). This combined method provides an excellent analytical technique of all analytes interest while providing a comprehensive sample purification that allows good recoveries of sensitive analytes. When analyzing jons at $m / z 405$ and 420 , the detection limit was met with spike $0.05 \mathrm{ng} / \mathrm{mL}$ using HRMS and 0.5 $\mathrm{ng} / \mathrm{mL}$ urinary concentrations by LRMS. Although the extraction with non-polar solvent gave lower extraction yields than that of polar organic solvents, the detectability of susbstance could be significantly increased if sufficient sample clean-up steps are taken to remove co-e]uting interference with non-polar solvent $n$-pentane as in this study. Combination of sample preparation techniques and analytical methods should be carefully selected because many steroid molecules are presented at various ranges of urinary concentrations and some steroids may be interfered to other steroids in chromatographic analysis. The experiments has proved that the HRMS method is clearly more efficient than the unit-resolution MS technique for the detection of many urinary steroids. ${ }^{13.19}$ However, the HRMS method also slightly hampered with biological backgrounds in some cases. This might be depressed by increasing resolution, and urinary interference could be reduced by changing the monitoring jons in LR/SIM-MS analysis as an altemative technique. Even with the HRMS method, comprehensive sample clean-up procedures might be needed especially in confinmation analysis because of the presence of overlapping peaks originating from the complex urinary matrices to get better verification.

Application to the urine samples. After extraction efficiency was evaluated to the analysis of spiked urine samples, the method was applied to urine samples spiked at the urinary concentration of $2 \mathrm{ng} / \mathrm{mL}$ and excretion urine samples after oral administration. When a combination method of Oasis HLB and MTBE extractions applied to stanozolol and boldenone administered samples, the present method provided the reliable results for the detection of urinary metabolites with apparent mass spectra (Figure 5). In addition, improved detectability of 3-OH-stanozolol was achieved by adding $d_{3}-3-\mathrm{OH}$-stanozolol as additional intemal standard (Figure 6). In the SIM chromatograms at $m / z 254$ and 560 for $3-\mathrm{OH}$-stanozolol detection, two ions were 

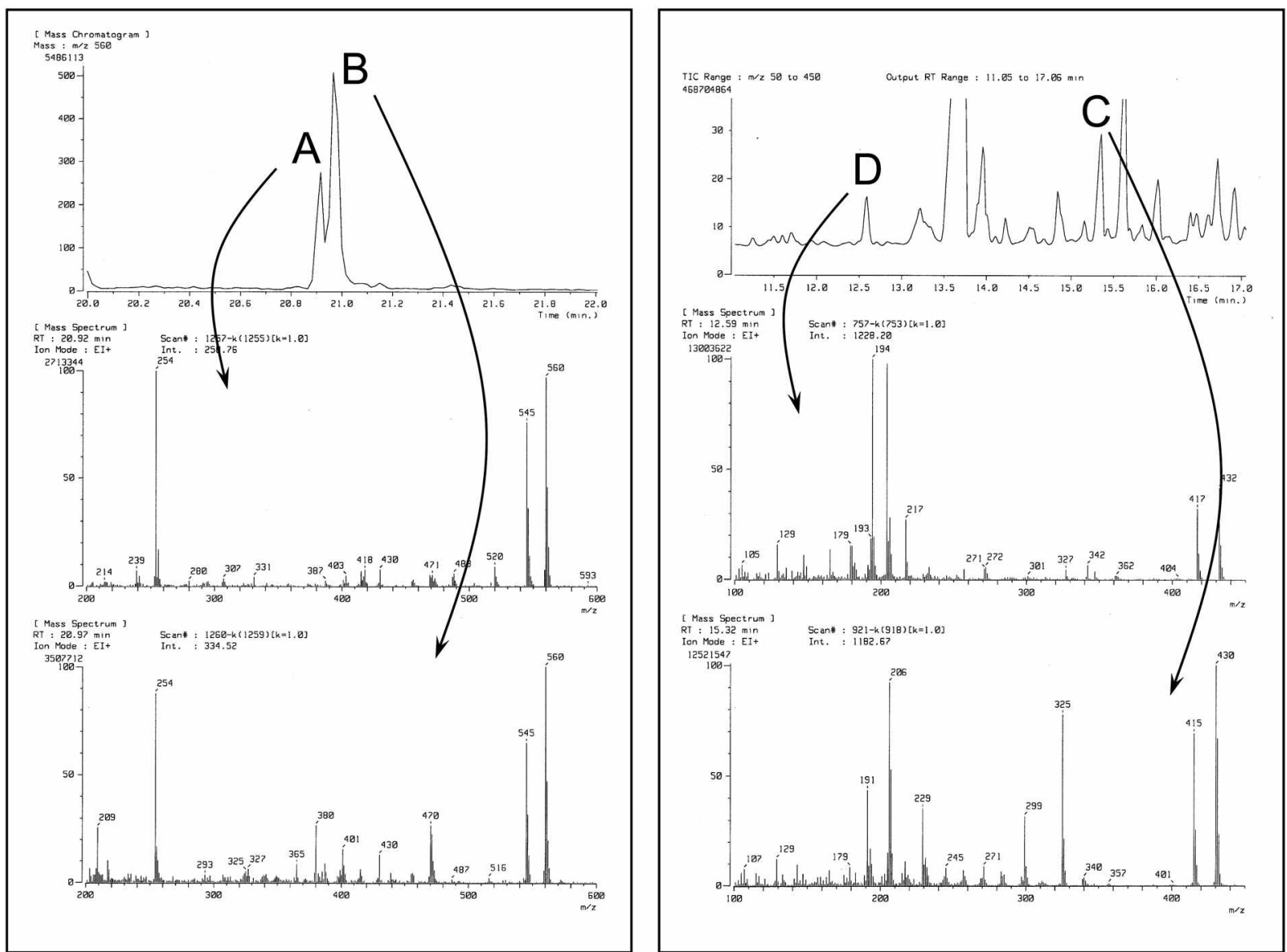

Figure 5. GC-HRMS chromatograms and mass spectra obtained from the urine samples of stanozolol and methyltestosterone adininistration. Detcetion of stanozolol metabolites, $(\Lambda) 4 \beta$-hydroxy-stanozolol and $(B)$ 3-hydroxy-stanozolol, and (C) boldenone and (D) its major metabolite were elearly detected. GC-HRMS conditions are the sane as in Figure 2.

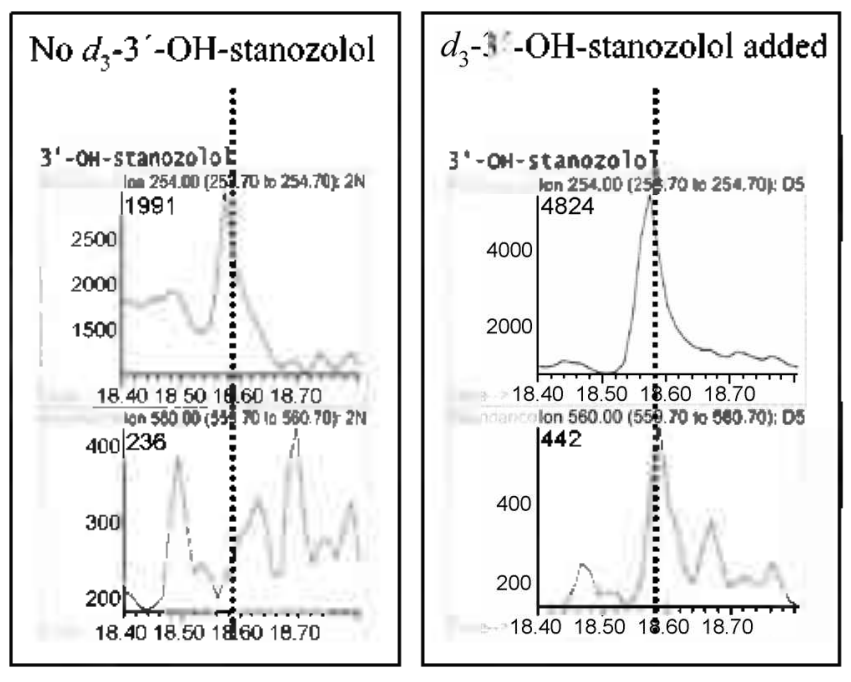

Figure 6. Comparison of GC-LR/SIM-MS chronatograms in detection of 3-hydroxy-stanozolol as its TMS derivative at $m / z 254$ and 560 . No peak at $m / z 560$ was detectable in sample not containing $d_{3}-3-\mathrm{OH}$-stanozolol (left), while both chromatograms at $m / 2254$ and 560 were clearly detected when $d_{3}-3-O H-$ stanozolol was added into the same sample at the urinary concentration of 5 $\mathrm{ng} / \mathrm{mL}$ (right). detected clearly when $d_{3}-3-\mathrm{OH}-\mathrm{stanozolol}$ was added, while no signal was detected at minor jon of $m / z 560$ in the sample without $d_{3}-3-\mathrm{OH}$-stanozolol. The partially deuterated compound may act as carrier along with co-elution with target analyte although 3-OH-stanozolol shows a strong thermal instability and sensitivity to active sites or disturbing matrix effects in $\mathrm{GC}$ analysis. ${ }^{18}$ This method can be employed to improve extraction efficacy within a reasonable time frame as suitable extraction in terms of sensitivity and selectivity for urinary androgenic steroids.

\section{Conclusion}

The present method optimized provides higher recoveries and selectivity as well as low background signals to improve detectability. In addition, this method can be expanded to include other steroid compounds and possibly other biological compounds, because they use a universal extraction sorbents and non-specific extraction conditions. The efficiency of sample preparations with different SPE cartridges and extraction solvents on analysis of urinary androgenic steroids, which are structurally diverse with functionalities that can be difficult to extract and purify efficiently in simultaneous was investigated. Working on expanding this 
evaluation to urinary estrogens and glucocorticosteroids is underway as we strive to deliver a comprehensive method for steroid analysis in doping control and clinical applications.

Acknowledgement. This work was supported by the intramural grants from Korea Institute of Science and Technology.

\section{References}

1. Chung, B. C.; Choo, H. Y. P.; Kim, T.; Eom, K.; Kwon, O.; Suh, J.; Yang, J.; Park. J. J. Antal. Toxicol. 1990, /4,91.

2. Schänzer, W.; Donike, M. Anal. Chim. Acto 1993, 275, 23.

3. Mueller, P. K.; Grosse, J.; Lang, R.; Thieme, D. J. Chromatogr, $B$ $1995,674, \mathrm{I}$.

4. Leinonen, A.; Savonen, L.; Kuoppasalmi, K. Proceedings of the Ith Cologne Workshop on Dope Analysis; Sport und Buch Strauss: Köln, Germany, 1994; p 25.

5. Geyer, H.; Engelke, U. M.; Schänzer, W.; Donike, M. Proceedings of the 11th Cologne Workshop on Dope Analysis; Sport und Buch Strauss: Köln, Germany, 1994; 97.

6. Massé, R.; Ayotte, C.; Dugal, R. J. Chromatogr. 1989, 489, 23.

7. Choi, M. H.; Chung. B. C. Analyst 2002, $126,306$.
8. Choi, M. H.; Kim, K. R.; Hong, J. K.; Park, S. J.; Chung, B. C. Rapid Commun. Mass Spectrom. 2002, 16, 2221.

9. Labadie, P.; Budzinski, H. Anal. Bioantal. Chem. 2005, 381, 1199.

10. Reddy, S.; Iden, C. R.; Brownawell, B. J. Anal. Chem. 2005, 77, 7032 .

11. Li, A. C.; Junga, H.; Shou, W. Z.; Bryant, M. S.; Jiang, X. Y.; Naidong. W. Rapid Conmun Mass Spectrom. 2004, 18, 2343.

12. Lin, W. C.; Chen, H. C.; Ding, W. H. J. Chromatogr, $A 2005$. $1065,279$.

13. Higashi, T; Yamaguchi, A.; Shimada, K.; Koh, E.; Mizokami, A.; Namiki, M, Anal. Broanal. Chem, 2005, 382, 1035.

14. Schänzer, W.; Delahaut, P.; Geyer, H.; Machnik, M.; Horning, S. J. Chronatogr, B 1996, 687, 93.

15. Bowers, L. D. Clin. Chem. 1997, 43, 1299.

16. Son, J.; Moon, J. Y.; Kim, S. A.; Cho, Y. D.; Kim, J. D.; Kim, D. H.; Choi, M. H. Talonta 2006, 70, 37.

17. Thieme, D.; Grosse, J.; Lang, R.; Mueller, R. K. Proceedings of the I3th Cologne Workshop on Dope Anatysis; Sport und Buch Strauss: Köln, Germany, 1996; p 285.

18. Fußhöller, G; Mareck, U.; Schänzer, W. Proceedings of the 23th Cologne Workshop on Dope Analysis; Sport und Buch Strauss: Köln, Germany, $2006 ; \mathrm{p} 14$.

19. Horning, S.; Donike, M. Proceedings of the 1th Cologne Workshop on Dope Analysis; Sport und Buch Strauss: Köln, Germany, 1994; p 155. 